\title{
Consideraciones teórico-metodológicas para el abordaje de la paternidad desde una perspectiva historiográfica
}

\author{
Leonor Cecilia Pinto Nińo
}

Doutoranda em História pela Universidade Federal de Juiz de Fora (UFJF)

\section{Resumo}

Este artigo apresenta algumas considerações teóricas para abordar a paternidade na historiografia. Esta tarefa é assumida desde a pergunta: o que é a paternidade? Realiza-se uma aproximação aos assuntos metodológicos, oferecendo grande importância à legislação como fonte, a partir da ideia de que a paternidade é uma instituição e como tal se institui pelas leis. A legislação é reconhecida como artefato cultural e literário, produto de lutas num campo de poder.

Palavras-chave paternidade, masculinidade, legislação, gênero.

\section{Resumen}

Este artículo presenta algunas consideraciones teóricas para abordar la paternidad en la historiografía. Esta tarea es asumida desde la pregunta: ¿Qué es la paternidad? Se efectúa una aproximación a los aspectos metodológicos, colocando en un lugar preponderante la legislación como fuente, a partir de la idea de que la paternidad es una institución y como tal se instituye sobre las leyes. La legislación es presentada como artefacto cultural y literario, producto de luchas en un campo de poder.

Palabras-clave paternidad, masculinidad, legislación, género. 


\section{Introducción}

$\mathrm{E}$ n 2002, Holanda fue el primer país en aprobar la adopción por parte de familias homoparentales y, actualmente, 27 países más han abierto esa oportunidad, entre éstos, 5 países latinoamericanosi. Se ha tratado de largos procesos de lucha, por conseguir el reconocimiento legal y social de las familias homoparentales u homosexuales y con ello, reivindicar sus derechos. Tal lucha no ha cesado con la oportunidad de adoptar en igualdad de condiciones a las de las familias constituidas sobre uniones heterosexuales o con el reconocimiento del derecho al matrimonio entre quienes la constituyen. Aún hay luchas por el reconocimiento social de las nuevas tipologías familiares que de ello se derivan. Buena parte de las sociedades latinoamericanas, incluidas aquellas que ya reconocieron tales derechos, continúan animosamente el debate en torno a quiénes pueden constituir una familia y quiénes pueden tener un lugar en el proceso de filiación de las nuevas generaciones².

El tratamiento dado a estas temáticas, entre otras, sugiere que persiste la comprensión de la familia desde una concepción estática, desconociendo las coordenadas de tiempo y espacio que la definen. Yendo más allá, la posibilidad de que una pareja homosexual tenga hijos parece suscitar la emergencia de lo ominoso y reavivar el gran temor a una posible borradura de la diferencia sexual, justo en un momento en que la autoridad patriarcal parece estar en declinación 3 . Igualmente, las posturas radicales y conservadoras observadas en algunos sectores de nuestras sociedades, que condenan moralmente tal posibilidad, parecen ubicar la consanguinidad en la base del parentesco y se asume que los parientes legítimos son exclusivamente aquellos con quienes se establece un vínculo consanguíneo. Se desconoce así el pluralismo de las tipologías familiares existentes, la diversidad en la elección subjetiva al asumir la parentalidad y el carácter eminentemente cultural de la naturaleza humana,

I Uruguay (2009), Argentina (20I0), Brasil (20I0), México (20I0 en el Distrito Federal y entre 2010 y 2017 en II de los 3i Estados), Colombia (2015).

2 Entre 2014 y 2017, en grandes centros urbanos latinoamericanos, se reportaron marchas multitudinarias en defensa del "diseño original de familia”, a imagen y semejanza de la Sagrada Familia, y en contra de lo que han denominado la "ideología de género". Al considerar que el género es una “ideología”, se niega su existencia y con ello las dimensiones psicológicas, socio-culturales e históricas de la sexualidad humana. Se trataría de un reduccionismo biologicista que se establece bajo la premisa de que reconocer el género es negar la existencia de Dios y la creación a su imagen y semejanza. Algunas de estas manifestaciones públicas mencionadas se reportaron en grandes ciudades de Brasil (Marzo de 2014), República Dominicana y Bolivia (Junio de 2016), Colombia (Agosto de 2016), México y Perú (Septiembre de 20I6), Panamá (Julio de 2017), Chile y Ecuador (Octubre de 2017) y Costa Rica (Diciembre de 2017). ROUDINESCO, Elizabeth. La familia en desorden. Barcelona: Editorial Anagrama, 2004. 
juzgando las formas actuales de familia como "desordenadas", en tanto desafían la biología, la tradición y el designio divino.

Definitivamente se han transformado la manera de ser familia y simultáneamente la conyugalidad, la parentalidad, la expresión de la sexualidad y todo aquello que define a cada uno de los subsistemas en su interior. Amplios sectores de las sociedades occidentales, que habían sido caracterizadas como patriarcales, testifican cambios en la manera como se asume la paternidad. Para Castells, se ha modificado la familia patriarcal y ella sustentaba el patriarcado, estructura primordial de la sociedad, caracterizada por "la autoridad, impuesta desde las instituciones, de los hombres sobre las mujeres y los hijos en la unidad familiar” ${ }^{4}$. Desde su perspectiva, la transformación vivida en la familia patriarcal ha influido, a su vez, sobre otros procesos interrelacionados: el trabajo y la conciencia de igualdad en las mujeres. En una larga cadena de causalidad relacionada con estos procesos se encuentran una economía informacional global, la influencia tecnológica al servicio de la reproducción, una organización feminista multifacética, las luchas de las mujeres con su consecuente vinculación al mundo laboral remunerado, los métodos de control natal, la fertilización in vitro y la manipulación genética, acontecimientos que se observan desde fines de los años 6o. En un intento de categorización se podrían ubicar estas realidades alrededor de la transformación económica, laboral y educativa; la transformación en la ciencia al servicio de la procreación y la sexualidad; el movimiento feminista; y, por último, la globalización.

Luis Flaquer recoge distintos términos que se han usado por diversos autores para denominar a las familias que han devenido a partir de ello: familia postpatriarcal, postnuclear, postfamiliar, individualista o relacional. Se tratan de distintos calificativos para un mismo fenómeno: nuevas formas familiares que superan la asociación que se efectuaba entre la figura del padre y la norma, la ley y la autoridad y la figura de la madre con la expresión de afecto y cariño. Para el autor, en el post-patriarcado, "las figuras del padre y de la madre irán difuminando progresivamente sus perfiles, que dejarán de ser nítidos y formarán combinaciones acordes con la personalidad de quienes las encarnen, sean varones o mujeres"s.

Parece que los actuales modelos de padres se caracterizan por posturas más democráticas, de mayor participación en la crianza de las nuevas generaciones y con mayor disposición hacia la expresión de afecto que la que tuvieron sus antecesores. De acuerdo con Montesinos, se trata de una nueva paternidad, relacionada

4 CASTELLS, Manuel. La era de la información: economía, sociedad y cultura. Volumen 3. México: Siglo XXI, 2000, p. I59.

$5 \quad$ FLAQUER, Luis. La estrella menguante del padre. Barcelona: Ariel, 1999, p. II. 


\section{R E V I S TA A N G L U S N O V U S}

con la emergencia de una masculinidad que reconoce a la contraparte, la feminidad, como un igual, y asume que los compromisos de la pareja, fuera de la reproducción biológica, se comparten de manera igualitaria. Así, la nueva paternidad, como expresión de una nueva masculinidad emergente, representa la capacidad crítica a los modelos tradicionales de los géneros, cuya esencia permite concentrar el poder en la figura masculina ${ }^{6}$

Seguramente se puede controvertir si al interior de los subsistemas conyugal y parental, en la familia postpatriarcal, efectivamente está generalizada una relación igualitaria y la expresión afectiva. Pero, sin duda, se asiste hoy a la manifestación de unas nuevas identidades masculinas, a nuevas formas de asumir el rol paternal y, en general, a unas nuevas relaciones entre los géneros.

Tampoco admite controversia que la paternidad, al igual que la maternidad, es una construcción colectiva e individual, dinámica y cambiante, acorde con los contextos históricos, sociales y culturales donde se desarrolla. En tanto construcción sociocultural, que ocurre en condiciones específicas de espacio y tiempo, las parentalidades son objeto de estudio de las Ciencias Sociales. Siguiendo a Norbert Elias, se reconoce que la paternidad, al igual que las demás relaciones que en el seno de la familia, se constituyen y se transforman en relación y correspondencia con la sociedad en la cual se integran. En este marco, "la familia [...] pueda ser vista como una figuración autónoma dentro de una figuración más amplia que es la sociedad estatal" 7 . Por ello, es pertinente abordar el cambio en su interior como objeto de estudio. En particular, dar un carácter histórico a las parentalidades, y su dimensión identitaria subjetiva, implica indagar por las condiciones políticas, económicas, sociales en las que se construyen y reconstruyen permanentemente. Siguiendo las recomendaciones de Joan Scott, este ejercicio supondría "romper la fijeza, descubrir la naturaleza del debate o represión que conduce a la aparición de una permanencia intemporal en la representación binaria del género" ${ }^{y}$ debe considerar las políticas, las instituciones y organizaciones sociales, junto a los símbolos culturalmente disponibles, los conceptos normativos que se expresan en los significados de estos símbolos, las doctrinas religiosas, políticas, científicas y educativas que aspiran a materializarlos y las identidades subjetivas que pueden ajustarse o tomar distancia de las prescripciones. Es preciso recordar que, de acuerdo con la autora, tales elementos asociados

6 MONTESINOS, Rafael. "La Nueva Paternidad: expresión de la transformación masculina”. In.: Polis: Investigación y Análisis Sociopolítico y Psicosocial, v.2, n.4, 2004, pp. 197-198.

7 ELIAS, Norbert. La civilización de los padres y otros ensayos. Bogotá: Editorial Norma, 1998, p. 445.

8 SCOTT, Joan. "El género: una categoría útil para el análisis histórico". In: NASH, Mary; AMELANG, James (Eds.) Historia y género: las mujeres en la Europa moderna y contemporánea. Valencia: Alfons el Magnanim, 1990, p. 45 . 
al género operan conjuntamente a manera de un sistema donde los elementos que lo integran se influyen mutuamente bajo un principio de causalidad circular.

Pero el interés académico sobre cada una de las parentalidades ha sido diferencial. La historia de la mujer y de la madre ha sido de obligatoria referencia, recibiendo así la mayor atención de investigadores en distintos campos de las Ciencias Sociales, mientras la masculinidad y la paternidad han sido relegadas a un plano secundario. La historiografía latinoamericana no escapa a esta tendencia, abordando poco el asunto. Sin duda, reconocer el vacío existente y volver la mirada a los hombres, y en particular a los padres, es nutrir el campo de investigación historiográfica alrededor de la familia.

Es indiscutible que la forma como se asume hoy la paternidad se ha transformado y estos cambios son el resultado de la convergencia de cambios en la dimensión subjetiva, social y cultural, pero ¿cómo ha ocurrido este cambio? Como ya se mencionó, desde una perspectiva historiográfica, son escasos los trabajos. Para el caso de Colombia, Rodríguez hace un recorrido desde la Colonia hasta el siglo XX para comprender la historia de esta institución, retomando las tipologías de familia, sus condiciones materiales, la vida conyugal, el lugar de los niños?. Para el siglo XX analiza las grandes transformaciones en los aspectos económicos y legislativos que impactan en la estructura familiar y la vida de la familia. Así mismo lo hacen: Chacón ${ }^{10}$, para el caso de España; Amorim"11, para Portugal; Gonzalbo y Rabell ${ }^{12}$ (2004), para México; Vera ${ }^{13}$, para Cuba; Rodríguez ${ }^{14}$ para Costa Rica; Pellicer y Quintero ${ }^{15}$, en Venezuela y

9 RODRÍGUEZ, Pablo. "La familia en Colombia”. In.: RODRÍGUEZ, P. (Comp.). La Familia Iberoamericana, I550-I980. Bogotá: Convenio Andrés Bello, Universidad Externado de Colombia, pp. 246289, 2004

ıo CHACÓN, Francisco. "La historia de la familia en España - Aproximación a un análisis”. In: RODRÍGUEZ, Pablo. (Comp.). La Familia Iberoamericana, I550-1980. Op.Cit. pp. 20-47.

II AMORIM, María Norberta. "La historia de la familia en Portugal: un espacio de diversidad Perspectiva demográfica en un tiempo largo”. In.: RODRÍGUEZ, Pablo. (Comp.). La Familia Iberoamericana, I5501980. Op. Cit., 2004, pp. 48-9I.

I2 GONZALBO, Pilar.; RABELL, Cecilia. “La familia en México”. In.: RODRÍGUEZ, Pablo. La Familia Iberoamericana, I550-I980. Op. Cit., pp. 92-I25.

I3 VERA, Ana. "La Familia Cubana en perspectiva” In.: RODRÍGUEZ, Pablo. La Familia Iberoamericana, I550-I980. Op. Cit., pp. I26-I65.

I4 RODRÍGUEZ, Eugenia. "Las Familias Costarricenses”. In.: RODRÍGUEZ, Pablo. La Familia Iberoamericana, I550-I980. Op.Cit., pp. I66-2II.

Is PELLICER, Luis.; QUINTERO, Inés. “'Matrimonio, familia y género en la sociedad venezolana. Siglos XVIII a XX”. In.: RODRÍGUEZ, Pablo. (Comp.). La Familia Iberoamericana, I550-Ig80. Op. Cit., pp. 212245 . 


\section{R E V I S T A A N GELUS N O V U S}

Mannarelli1' ${ }^{16}$, en Perú, entre otros. Todos estos destacados trabajos abordan la transformación de la institución familiar en sus respectivos contextos y si bien aluden al cambio del rol de los padres ante sus hijos, no abordan específicamente la transformación de la paternidad como institución, ni su lugar social.

Para el caso de Chile se encuentra a Fernández, quien aborda las identidades masculinas populares en el siglo XIX y específicamente las imágenes que se divulgan de los hombres ${ }^{17}$. Encuentra que los hombres de sectores pobres son asociados con las imágenes del borracho, el degenerado, el insurrecto, el asesino, el irresponsable, el temible, representaciones emanadas desde la élite. De tal manera, se pregunta por las imágenes masculinas, pero no considera las maneras como se representan los padres.

Para el contexto colombiano, Pinto, abordando los periodos comprendidos entre 1879-1979 ${ }^{18}$ y $1980-1985^{19}$ desde una perspectiva histórica, encuentra que la modificación en las formas que hoy asume la paternidad no puede limitarse al reconocimiento de la transformación percibida a partir de los años 1960 y es en cambio un proceso de vieja data. Encuentra que, si bien el Código Civil de I879 enaltece al padre, ubicándolo en un lugar de autoridad, similar al de un pater familias romano que detenta la potestad marital, patrimonial y patria potestad, a partir de I892 con la promulgación de legislación educativa se le depone paulatinamente, proceso que será vivido a lo largo del siglo XX. La legislación promulgada en ese periodo es presentada como reflejo de la transformación sufrida por la paternidad como institución y, en una relación de causalidad circular, contribuiría a su declinación.

A partir del abordaje de unos procesos que devienen en la actualidad en múltiples identidades y roles, donde se reconoce, parafraseando a Knibiehler, que no se trata del fin de los padres, ni de la estructura patriarcal sino de su transformación ${ }^{20}$, hacia la reconfiguración de distintas identidades y formas de relación de los padres consigo mismos, con las madres, con los hijos y el entorno, cabe la pregunta: ¿Qué es ser padre?

I6 MANNARELLI, María Emma. "Vínculos familiares y fronteras de lo público y lo privado en Perú". In.: RODRÌGUEZ, P. (Coord.). La Familia Iberoamericana, I550-1980. Op. Cit., pp. 326-368.

FERNÁNDEZ, Marcos. "Pobres, borrachos, violentos y libres: notas para reconstrucción de identidades masculinas populares del siglo XIX”. In.: OLAVARRÍA, José.; PARRINI, Rodrigo. (Eds). Masculinidad / Identidad, sexualidad y familia. Santiago de Chile: FLACSO-UAHC, 200o, pp. 47-58.

PINTO, Leonor Cecilia. La paternidad en Colombia entre 1879 y 1979. Una exploración desde la legislación. 2015. I59 f. Disertación (Maestría). Facultad de Humanidades, Universidad del Valle, Cali, 2015.

I9 PINTO, Leonor Cecilia. La paternidad en Colombia entre Ig80 y Iggr. Una exploración desde la legislación. 2017. 79f. Investigación (Pregrado). Facultad de Humanidades, Universidad del Valle, Cali, 2017.

20 KNIBIEHLER, Yvonne. "Padres, patriarcado, paternidad'. In.: TUBERT, Silvia. (Edit.). Figuras del padre. Madrid: Cátedra, 1997. 


\section{Paternidad y masculinidad}

Para Kniebiehler, la pregunta por la paternidad implica interrogarse inicialmente por masculinidad ${ }^{21}$. Al rastrear este concepto se hallan múltiples definiciones. Gutmann encara el problema que esto implica, categorizando estas definiciones en cuatro enfoques, cada uno de los cuales gira alrededor de un concepto clave ${ }^{22}$. En primer lugar estarían aquellas perspectivas que sitúan la masculinidad del lado de la "identidad" y comprenden lo masculino como todo aquello inherente a los hombres, es decir, sus acciones, sus pensamientos y sus sentimientos. El segundo enfoque, articulado en torno al concepto de "hombría", recoge las conceptualizaciones que aluden a la masculinidad como un proceso, como un ideal a ser alcanzado, corresponde a lo que los hombres dicen, piensan y hacen para definirse y distinguirse a sí mismos como hombres. El tercer concepto, centrado en "virilidad", asume la existencia de una cualidad que define diferentes grados de masculinidad. Finalmente, otro grupo de definiciones enfatiza en los "roles", considerando que aquello que distingue a los hombres es el resultado de una negociación entre ellos y las mujeres, en la cual ellas ocupan un lugar central.

Seguramente los enfoques presentados, en algunos momentos, se entrecruzan en tanto las categorías y sus conceptos-clave no son excluyentes entre sí. Al reconocer que a la masculinidad tiene un componente biológico, psicológico, social, cultural e histórico, a ella le corresponde una dimensión identitaria que define lo que un hombre es, y otra dimensión comportamental donde se incluyen los roles y guiones de comportamiento que le corresponden y que resultan ser prescripciones socio-culturales. Se entiende, además, que la masculinidad se aprende en el marco de la socialización, en una cultura y tiempo específico que la dota de contenidos y que establece un ideal. De igual manera, se reconoce que tal ideal sería inalcanzable completamente, siendo posible establecer niveles de "hombría" o "virilidad" de acuerdo con la proximidad o distanciamiento del modelo.

Connell plantea que la masculinidad es una construcción social que resulta de la influencia de una multiplicidad de factores y ámbitos como la familia, la escuela, los medios de comunicación, la religión y la conformación de la sociedad, pero en todos los casos depende de un sistema de relaciones de género y este sería una estructura de relaciones sociales que, para fines analíticos, puede subdividirse en el trabajo, el poder y la cathesis ${ }^{23}$. El trabajo lo

2 I Ibid.

22 GUTMANN, Matthew. Ser hombre de verdad en la Ciudad de México - Ni macho ni mandilón. México: Colegio de México, 1996.

23 CONNELL, Raewyn. "Hegemonic Masculinity and Emphasized Feminity". In.: Gender and Power: Society, The Person, and Sexual Politics. Standford: Standford UP, 1997, p. 183-190. 


\section{R E V I S T A A N GELUS N O V U S}

constituyen las relaciones de producción y las divisiones del trabajo de acuerdo con el género, que le son inherentes; en las relaciones de poder define las relaciones de dominación masculina y subordinación femenina; la cathesis corresponde a la carga emocional que representan las relaciones sociales, la organización del deseo, los sentimientos y la sexualidad. Con respecto a ello, la masculinidad sería, simultáneamente, la posición en las relaciones de género, las prácticas por las cuales los hombres y mujeres se comprometen con esa posición de género, y los efectos de esas prácticas en la experiencia corporal, en la personalidad y en la cultura. La masculinidad es entonces un aspecto de la identidad de género y como tal no es un hecho natural o biológico, sino una construcción cultural que se reproduce socialmente y que, por tanto, no se puede definir fuera del contexto socioeconómico, cultural e histórico en que están insertos los hombres y las mujeres ${ }^{24}$.

Así, la masculinidad puede entenderse como una expresión de la convicción que desarrolla una persona al reconocerse como perteneciente al género masculino, como diferente al femenino. Correspondería entonces al conjunto de atributos, valores, funciones y conductas que resultan esenciales a quien aspira a definirse como hombre en una cultura. Pero no se trata de un único referente. Seidler ${ }^{25}$ precisa la multiplicidad de referentes se presenta porque a lo largo del proceso de socialización tienen lugar diferentes influencias sociales y culturales en las cuales se vive y de las que se pueden mencionar la clase, la religión, la etnia, la convivencia urbana o rural y, primordialmente, una serie de influencias dadas por la familia, como la ética y la moral.

Como plantea Bourdieu, es incuestionable que ser hombre es encontrarse en una posición de poder ${ }^{26}$. Pese al lugar de la cultura en la masculinidad, de acuerdo con él, la dominación masculina debe su eficacia a que en ella convergen dos operaciones: se legitima una relación de dominación al inscribirla en la naturaleza biológica; y esta es, en sí misma, una construcción social naturalizada. Tras reconocer la existencia de múltiples masculinidades y explorarlas, Kimmel ${ }^{27}$ precisa que no todo hombre se halla en tal posición de poder. Dentro de cada sociedad y estrato específico predominaría uno de los tipos de masculinidad, al cual se denominaría masculinidad hegemónica. Tal masculinidad consistiría en una forma culturalmente idealizada, un proyecto personal y colectivo, que se presenta como natural y

24 En torno a este asunto pueden verse los trabajos de VALDÉS, María Teresa; OLAVARRÍA JOSÉ. (eds.). Masculinidad/es - Poder y crisis. Santiago de Chile: Ediciones de las Mujeres, No.24, Isis Internacional, FLACSO, Santiago de Chile, 1997 y VIVEROS, Mara. De quebradores y cumplidores. Sobre hombres, masculinidades y relaciones de género en Colombia. Bogotá: Universidad Nacional de Colombia, 2002. SEIDLER, Víctor. Achiles Hell Reader: Men, Sexual Politics and Socialism. London: Routledge, 1991. BOURDIEU, Pierre. La dominación masculina. Barcelona: Anagrama, 2000. María Teresa; OLAVARRÍA JOSÉ. (eds.). Masculinidad/es - Poder y crisis, Op. Cit. 
que está socialmente sustentado. El modelo hegemónico de masculinidad corresponde a los valores predeterminados por el discurso de los actores sociales dominantes, tales como el Estado, la Iglesia, la Escuela y los medios de comunicación. De acuerdo con su propuesta, se trata de un modelo ideal que resulta inalcanzable por parte de los hombres reales y concretos, pero que ejerce su influencia sobre todos ellos.

En el concepto de masculinidad hegemónica son fundantes dos ideas: la heterosexualidad como norma; y la homofobia o violencia contra quien la trasgrede como intento de restablecer el orden. Badinter identifica que, en la sociedad contemporánea, el ideal masculino, equiparable a la masculinidad hegemónica, tiene cuatro consignas básicas: no ser afeminado; ser una persona importante; ser fuerte, recurriendo a la violencia si es necesario; y capaz de enviar "todo al diablo" en caso necesario ${ }^{28}$. De acuerdo con la autora, el "verdadero hombre" está exento de toda marca de feminidad, por lo cual debe renunciar a la expresión del afecto, la ternura y la sensibilidad, cualidades consideradas femeninas y deberá demostrar su fuerza, distanciándose de un niño desvalido, una mujer o un homosexual. De igual manera, se exige al hombre ser una persona importante y con ello el éxito, como fuente de poder y prestigio, pasa a ser una cualidad determinante. Además, el mandato le impone la superioridad con respecto a otros hombres, de allí la búsqueda del reconocimiento en el ámbito público a través del trabajo y el éxito económico. El trabajo masculino es entonces la producción, mientras que para las mujeres es la reproducción. Así las cosas, el hombre está cuestionado permanente, y por ello obligado a dar muestras públicas de su condición de hombre. Por ello, puede incurrir en imprudencias, abusos de poder, actos de humillación y sometimiento al considerarse amenazado. Este hombre estaría, según la autora, más preparado para la guerra y la muerte que para el matrimonio y el cuidado de su descendencia. Con ello, desde la temprana infancia la socialización mutilaría la expresión del afecto y toda sensibilidad considerada femenina, posibilitando encarar cada consigna para llegar a ser "un hombre de verdad". Para la autora, el hombre no nace hombre, se hace; y lo hacen los mismos hombres, a través de la educación y el sistema cultural. La creación de otros hombres remite a la paternidad: es fundamental reinventar al padre mediante el reconocimiento que los hombres engendran otros hombres.

La paternidad expresa entonces uno de los roles de género referido a la relación que establecen los hombres con su descendencia inmediata, pudiendo ser ésta biológica o adoptada socialmente. Ella es "la culminación de la identidad masculina, su estado pleno, su mayor solidez” ${ }^{29}$. Se trata de una institución socio-cultural y, como institución, puede ser 


\section{R E V IS TA A N GELUS NOVUS}

comprendida como una estructura de normas que fijan y conservan un juego de roles sociales. Así, ellas representan un equilibrio social entre poder y beneficios y se hallan interrelacionadas. Particularmente, la paternidad, se inscribe dentro de otra institución, la familiar, la cual está enmarcadas por normas que definen la constitución de la pareja sexual y de filiación intergeneracional ${ }^{\circ}$ y se sustenta por la institución del matrimonio.

Douglas North entiende las instituciones como las reglas del juego en la sociedad, enfatizando en su aspecto prescriptivo y de regulación cuyo propósito sería promover un comportamiento específico, definiendo posibilidades y restricciones para ello ${ }^{31}$. Tales restricciones pueden ser informales, y entre ellas menciona las costumbres, los códigos tácitos de conducta, las tradiciones y los tabúes. Entre las restricciones formales estarían las normas consignadas en las constituciones, las leyes o derechos de propiedad. En este marco, la paternidad como institución es prescriptiva de unas maneras de asumirla y las leyes recogen algunas de estas prescripciones. Parafraseando a North, la paternidad, con las posibilidades y restricciones que plantean a la conducta de los padres, permite la generación de escenarios de certeza en la interacción en la familia y en la sociedad y con ello la reducción de la incertidumbre y del riesgo, así como los costos asociados a estos intercambios. De igual manera, es preciso tener en cuenta que las instituciones se transforman permanentemente, bajo la presión de múltiples factores, tanto de orden político como económico, por ello, el cambio histórico puede ser evidenciado y comprendido a través del cambio en las instituciones, en este caso la paternidad.

Al ser la paternidad incierta por naturaleza, se apoya en otra institución: el matrimonio. De tal manera, padre es quien demuestre las justas nupcias: Pater is est quem justae nuptiae demonstrant. Esta fórmula del derecho romano implica que

[...] el hijo de la mujer casada tiene padre cierto; el marido de su madre. Esta máxima jurídica [...] establece una presunción jurídica .'juris tantum' a cerca de la certeza de paternidad, en favor primordialmente del hijo, pero también con respecto al padre y a la madre. Todas las legislaciones han establecido limitados supuestos para administrar la prueba en contrario. Esta presunción tiene su base en los deberes que nacen para ambos cónyuges, de cohabitación y fidelidad recíproca, fidelidad como deber mucho más riguroso para la mujer en razón precisamente de otorgarle paternidad cierta a su marido. De allí que cuando una mujer no casada da a luz un hijo, no existen bases jurídicas,

Identidad, sexualidad y familia. Chile: FLACSO, 2000, p.75.

HERBORN, Göran. Familias en el mundo - Historia y futuro en el umbral del Siglo XXI. Santiago de Chile: Naciones Unidas, CEPAL, Colegio Sueco de Estudios Avanzados de Ciencias Sociales, 2014.

3I NORTH, Douglas. Instituciones, cambio institucional y desempeño económico. México: Fondo de Cultura Económica, 2006. 
aunque las puede haber casi evidentes por otras circunstancias, para atribuirle la paternidad a cierto y determinado varón $3^{2}$.

En la anterior perspectiva, la Paternidad remite a la procreación y, en tal sentido, se asocia inexorablemente a la maternidad. Como plantea Sivia Tubert, parafraseando a Carol Delaney, tampoco la procreación puede asumirse como un hecho meramente biológico,

la procreación se entiende como una construcción cultural que expresa y refleja categorías y significaciones de la cultura de la que forma parte. En consecuencia, paternidad y maternidad se presentan como conceptos articulados en un sistema del que no se puede abstraer sin correr el riesgo de desvirtuar su sentido 33

Por tanto, paternidad no significa meramente el reconocimiento de un vínculo fisiológico entre un hombre y su hijo, análogo al que existe entre una mujer y su hijo. Es decir, la paternidad no es el equivalente semántico de la maternidad, por cuanto, como lo sostiene Tubert, el significado de la paternidad incluye elementos o referentes que expresan un significado social, por ejemplo, las relaciones de género, de poder y el de parentesco. La paternidad entonces remite a la relación con los demás integrantes de una familia y también al lugar que ocupa una familia dentro de los órdenes económico, político y sociocultural en un contexto y un momento histórico determinado. Igualmente, en tanto derivada de un rol de género, la paternidad "es una forma primaria de relaciones significantes de poder" ${ }^{34}$. Con respecto a las relaciones padres-hijos, Elias plantea que ellas se constituyen en una relación de dominación, con una desigual distribución de poder, dado que los padres históricamente han tenido el monopolio de su ejercicio 3 . Knibieheler reflexiona sobre este punto afirmando que "Los padres de las jóvenes generaciones han de saber que de aquí en adelante tendrá que manejar tres tipos de relaciones, y ante todo construirlas: con una mujer madre, con los poderes públicos y con los hijos que ya no son, e indudablemente no volverán a ser jamás, únicamente suyos" 36 .

32 MONTERO, Sarah. "Evolución legislativa en el tratamiento de los hijos extramatrimoniales (México Independiente)". In.: Memoria III Congreso Histórico del Derecho Mexicano. México: Universidad Nacional Autónoma de México, 1984, p. 432. TUBERT, Silvia. Figuras del padre. Op. Cit., p. 35. SCOTT, Joan. "El género: una categoría útil para el análisis histórico". Op.cit. p. 47. KNIBIEHLER, Yvonne. "Padres, patriarcado, paternidad". Op.Cit. p. I35. 


\section{R E V I S T A A N GELUS N O V U S}

En el mismo sentido, Anatrella enfatiza que la paternidad no se puede asumir de manera reduccionista como un acto puramente biológico, de procreación ${ }^{37}$. De acuerdo con la autora, si bien la concepción le da origen, no se agota en ello su sentido; "la misma palabra padre no designa al progenitor, al individuo padre, sino lo que concierne a la función paterna, es decir, al papel simbólico que va asociado al nombre de esa figura." ${ }^{3}$. De tal manera, este papel podrá ser ocupado no necesariamente por el padre, sino también por otra persona que viva cerca del niño y que asuma su protección y su cuidado. Se considera importante diferenciar los tipos de paternidad que derivan de la anterior precisión. Se ha planteado, incluso en el lenguaje popular, el lugar del "padre social” o "de crianza”, diferenciado del "padre biológico". Esta distinción permite examinar el rol social del padre, abstrayéndolo de la biología y haciendo referencia a quienes no son padres biológicos pero asumen el rol paterno en un sentido social. Tal escisión considera tácitamente unas expectativas y prescripciones sociales y culturales frente al buen padre. Seguramente la paternidad social resulta ser más valorada que la paternidad biológica desde el esfuerzo sostenido que implica la crianza en el plano económico y afectivo, además de la elección voluntaria que representa.

\section{Paternidad, cultura e historia}

La doble naturaleza de la paternidad, biológica y social, daría cuenta de su carácter socio-cultural e histórico:

La paternidad social, ampliamente aceptada en nuestras sociedades, que convierte en padres a hombres por adopción legal, o acordada incluso sin referendo legal, muestra que la paternidad tiene una dimensión sociocultural, porque es una construcción social que se modifica históricamente. La paternidad no está dada de antemano, de forma natural. Como toda conducta humana puede o no asumirse, aceptarse o rechazarse, y su forma aceptable dependerá de lo que socialmente se espere de ella en un momento histórico determinado39.

Desde esta perspectiva socio-cultural, Fuller reconoce que la definición de paternidad recoge lo biológico y lo social, como un campo de prácticas y de significaciones,

37 ANATRELLA, Tony. La diferencia probibida - Sexualidad, educación y violencia. Madrid: Editorial Encuentro, 2008, p. 54 .

38 ANATRELLA, Tony. La diferencia probibida - Sexualidad, educación y violencia. Madrid: Editorial Encuentro, 2008, p. 54 .

39 ORTEGA, Manuel; CENTENO, Rebeca. y CASTILlO, Marcelina. 2005. Masculinidad y factores socioculturales asociados a la paternidad en cuatro paises de Centroamérica. Managua: UNFPA-CEPAL, 2005 , p. 24 
tanto culturales como sociales que giran alrededor de la reproducción, el vínculo que se establece o no con la descendencia y a su cuidado $4^{\circ}$. A modo de ver de la autora, este campo de prácticas y significaciones es el resultado de lo que denomina un entrecruzamiento de discursos sociales, de carácter prescriptivo, que divulgan valores y modelan comportamientos a través de guiones de carácter reproductivo y parental. Estos guiones modeladores son adaptados al momento del ciclo vital de los integrantes de la familia y las relaciones que se establecen entre los cónyuges y entres ellos y los hijos. De igual manera, están ajustados a jerarquías de edad, género, clase, raza y etnia. Pero más que una respuesta a estas variables, Alatorre y Luna plantean que son ellas las que permiten comprender la manera cómo se define la paternidad en un contexto determinado, al ser las características distintivas de los grupos humanos ${ }^{41}$. De tal manera, las prácticas e interpretaciones que se hacen alrededor de la paternidad son múltiples.

Los estudios antropológicos e históricos permiten visualizar la variabilidad históricocultural de la paternidad y su carácter construido, ligado a determinados contextos políticos, económicos, sociales, así como a ciertas configuraciones simbólicas e imaginarias. La paternidad será construida de maneras específicas en cada sociedad, en un momento histórico dado y será afectada por los procesos socioculturales que se desplieguen en dicho momento. Así, se confirma que no hay una paternidad para todas las culturas y sociedades humanas.

Como fenómeno cultural, social y subjetivo, la paternidad tiene una enorme diversidad dentro del mismo individuo, entre los individuos de un mismo contexto sociocultural y en diferentes momentos históricos y es estructurada, definida e interpretada en un contexto sociocultural con sus distancias sociales y dimensiones ${ }^{42}$. Para entender cómo se define la paternidad en un contexto determinado, es necesario considerar lo que comparten y lo que distingue a los diferentes grupos humanos: edad, etnia, orígenes sociales y sector de residencia; ya que las prácticas y significados de la paternidad no son homogéneos y universales. Por consiguiente, es necesario reconocer la multiplicidad de representaciones, prácticas e interpretaciones que los hombres hacen de su masculinidad y de la paternidad. La paternidad también es entendida como una relación social en la que se interrelacionan mecanismos sociales de regulación, mecanismos culturales de representación y mecanismos subjetivos que dan sentido a la vivencia personal. La paternidad se construye por medio de

40 FULLER, Norma. (Ed.). Paternidades en América Latina. Lima: Pontificia Universidad Católica del Perú; Fondo, 20oo.

4I ALATORRE, Javier. y LUNA, Rafael. "Significados y prácticas de la paternidad en la Ciudad de México". In.: FULLER, N. (Eds.). Paternidades en América Latina. Lima: Pontificia Universidad Católica del Perú, Fondo, 2000. pp. 24I-275.

42 Ibid. 


\section{R E V I S T A A N G E L U S N O V U S}

procesos socioculturales y subjetivos que dan lugar a las prácticas y a significaciones de la relación con los hijos e hijas. Dicha relación sólo se puede entender tomando en cuenta el posicionamiento tanto de los hombres como de las mujeres, con relación a los hijos e hijas.

En este orden, se reconoce la paternidad como una posición y función que se modifica históricamente según los cambios sociales, y tiene variaciones notables de una cultura a otra, así como en las distintas clases sociales y etnias dentro de un país. Asimismo, tiene especificidades de acuerdo con las particulares historias de vida de los hombres, y significados distintos a lo largo del ciclo de vida de un mismo sujeto. La paternidad responde, entonces, a las expectativas, la cultura, las necesidades económicas y las propias experiencias de los hombres como padres y como hijos.

Tras realizar exploraciones etnográficas, Silvia Tubert advierte que es preciso superar aquello que daba por sentado y reconocer que, además de ser múltiples, las paternidades no tienen en su base la relación sexual entre la madre y quien la asume, no siempre son encarnadas por hombres, ni por una sola persona, la filiación no está determinada biológicamente y las ideologías de la procreación son también formas sociales:

Los atributos de la paternidad (...) no suelen estar focalizados en una figura única, ni hay una relación biunívoca entre padre e hijo/a; la paternidad se diferencia claramente de la generación; las ideologías de la procreación aparecen como metáforas de la paternidad social y no a la inversa: la relevancia del progenitor depende de la noción de filiación, que es un concepto social y no biológico; la relación sexual entre la madre y la persona que detenta las responsabilidades paternas no es un factor constante y necesario, y; la persona que ostenta la parte fundamental del haz de responsabilidades recíprocas que configuran la paternidad no es necesariamente de sexo masculino ${ }^{43}$.

En diferentes sociedades, en especial las Occidentales, el padre ha tenido las funciones de otorgar el apellido al hijo, sostenerlo económicamente y socializarlo. Al respecto, Narotzky encuentra que las funciones paternas son: "cuidado, acceso a recursos económicos, políticos, simbólicos, transmisión de conocimientos y de bienes"44; están articuladas en el sistema de parentesco, filiación y transmisión de una sociedad determinada pueden ser ejercidas por personas diferentes de quien engendró al hijo, tales como el hermano de la madre o por una mujer, o padre sustituto. Pero independientemente de ello, para la organización subjetiva y social la función paterna resulta definitiva:

43 TUBERT, Silvia. Figuras del padre. Op. Cit., p. 22.

44 NAROTZKY, Susana. "El marido, el hermano y la mujer de la madre: algunas figuras del padre". In.: TUBERT, Silvia. (Comp.). Figuras del padre. Op.Cit., p. 2 I2. 
Si para la existencia de la humanidad el padre biológico cumple la función de iniciador de la vida, para la permanencia de la sociedad, como principio organizador, su función es fundamental. La posición asumida por los padres y las relaciones entre ellos, van a incidir en la forma como los hijos interioricen tanto al padre como a la madre y en la forma como asuman posteriormente el ejercicio de la maternidad y la paternidad. Se podría afirmar entonces, que el ser padre o madre se aprende desde la infancia. Las experiencias vividas en la infancia con los padres también inciden en la formación de su personalidad y en su identidad psicosexual 45 .

Una vez efectuadas estas consideraciones teóricas básicas es posible abordar algunas implicaciones metodológicas que de ellas derivan.

\section{La legislación fuente fundamental en el abordaje de la paternidad}

Antes de considerar el camino metodológico para abordar la paternidad en una perspectiva historiográfica, debe considerarse, como ya se mencionó, que la paternidad tiene un carácter distinto a la maternidad, porque para ésta existe una evidencia biológica, la gestación. A falta de tal evidencia, "la paternidad se evidencia por medio de la ley, [...] estaba instituida, en tanto que la maternidad no lo estaba" ${ }^{46}$. Al tratarse de una institución, la paternidad alude a un conjunto político, jurídico y social que se constituye su referente cultural y sostén en una sociedad determinada ${ }^{47}$. Si legislación es reconocida como son fundamento y sostén de la institución del padre ${ }^{48}$, ocuparía un lugar central como fuente primaria en la investigación sobre ella.

A partir de esto, podría inferirse que la modificación en la base jurídica transformaría la institución que sostiene y con ello, la pregunta por la transformación de la paternidad, como institución, que hoy nos pone ante múltiples identidades, no sólo masculinas sino también paternas, podría encararse analizando las leyes y sus transformaciones.

De tal manera, una conjetura orientadora sería que las transformaciones en la legislación, alrededor de la paternidad, reflejarían los cambios sociales y culturales de la época

LAMUS, Doris. "Representaciones sociales de maternidad y paternidad en cinco ciudades colombianas". In.: Reflexión Politica, Bucaramanga, v. I, n. 2, p. 7-15, 1999, p. 7.

46 KNIBIEHLER, Yvonne. "Padres, patriarcado, paternidad". Op. Cit., p. I20.

47 HURSTEL, Françoise. "Las funciones del padre en la sociedad contemporánea post-industrial: riesgos antropológicos y subjetivos”. En: ZAOUCHE-GAUDRON, Chantal. (Ed.). La Problématique Paternelle. París: Eres, 200I, p. 6I-74.

48 KNIBIEHLER, Yvonne. "Padres, patriarcado, paternidad". Op. Cit. 


\section{R E V I S TA A N G E U S N O V U S}

en que se promulgan. Como fundamento y reflejo de transformaciones en la esfera social, el derecho, según Pierre Legendre, es "la marea simbólica de lo social” 49. En este mismo sentido, Kevelson plantea que la terminología, conceptos e ideas en un sistema de derecho son signos que ofrecen una comprensión profunda de los valores de una sociedad y de la relación entre el discurso legal y la práctica cotidiana ${ }^{50}$. En sus planteamientos se logra reconocer la idea de que estos sistemas se transforman continuamente para corresponder a la conciencia social y a las normas sociales variables de cada comunidad. Sostiene que el estudio de un sistema de signos en una doctrina legal o en untérmino legal incluiría la identificación de su origen, de su valoración dentro de la sociedad específica y de sus cambios a través del tiempo. De este modo, un sistema de signos legales puede servir de referencia para esclarecer las relaciones interpersonales y los intercambios de una comunidad;

\footnotetext{
Mas, como los preceptos del derecho cambian siempre, se puede ver el estudio del discurso legal como un diálogo abierto donde, de vez en cuando, surgen nuevos signos inesperados que profundizan nuestro entendimiento de las actividades y de las actitudes de una sociedad ${ }^{5}$.
}

Junto a la anterior oportunidad que la legislación tiene como fuente, también existen limitaciones inherentes a la característica que le son propias y que no se pueden desconocer. Las leyes dan cuenta de las coyunturas, de acontecimientos concretos e incluso de tendencias, más que de las estructuras y fenómenos de larga duración. Ellas son también instrumentos de poder y dominación, que intentan organizar el dominio de lo doméstico, de regular y ordenar, a través de sus prescripciones, lo cual podría llevar a desconocer el lugar de los padres en el ámbito doméstico. Para encarar estas particularidades, un diseño metodológico que considere el entrecruzamiento con las condiciones sociales, políticas y económicas, en las cuales las leyes se promulgan, posibilitarían trascender lo coyuntural y lo concreto para permitir un acercamiento a la dinámica de una sociedad. Igualmente, es preciso tener en cuenta, como plantea Poole, que aunque las leyes sean prescriptivas e intenten uniformizar, unificar, no dejan de existir formas de resistirse a ellas, asumiendo conductas distintas a las prescritas ${ }^{2}$, que bien valdría la pena considerar en un trabajo de investigación historiográfica que tenga a las leyes como fuente central. Frente a la última de las dos limitantes mencionadas, podríamos agregar que la figura que se divulga en la legislación

49 Citado por TUBERT, Silvia. Figuras del padre. Op. Cit., p. 296.

so Citada por STONE, Marilyn. “Desde las Siete Partidas a los Códigos Civiles norteamericanos”. In.: Actas Irvine - 92, XI Congreso de la Asociación Internacional de Hispanistas, p. 25-33, 1994. Disponible en: $<$ http://cvc.cervantes.es/literatura/aih/pdf/II/aih_II_3_oo5.pdf>. Accesado en abril 6 de 2019.

5I STONE, Marilyn. “Desde las Siete Partidas a los Códigos Civiles norteamericanos”. Op. Cit., pp. 25-26.

52 POOLE, Deborah. Visión, raza y modernidad. Lima: Casa de Estudios del Socialismo, 2000. 
podría consistir en una representación estandarizada que corre el riesgo de borrar las particularidades de las familias, sosteniendo un modelo ideal, en un lugar mítico. En la medida en que la legislación, bajo el principio de igualdad, tiene una pretensión universalizadora, ella puede desconocer las culturas locales, las particularidades sociales y aspectos de orden histórico, deviniendo en "regímenes de representación" descontextualizados, lugares modernizados de violencias3. En este sentido, junto a la revisión del conjunto jurídico frente al tema, sería pertinente la pregunta por las representaciones y roles que se promueven alrededor de la figura de padre, y que irán consolidando identidades parentales, y su correspondencia con la compleja realidad de las familias para un tiempo y lugar específico. De igual manera, explorar las prácticas concretas de los padres, en el espacio doméstico, permitiría reconocer la existencia de las propias “agencias” en las que se articularían sus identidades. Se partiría así del reconocimiento de unos padres, que tiene la particularidad de ser agentes de la construcción de su propia identidad, participando de la organización de una posicionalidad y subjetividad múltiples, bajo determinadas condiciones, dentro de un campo de relaciones de poder, parafraseando a Coronil ${ }^{4}$ y no son simples cumplidores $-\mathrm{o}$ incumplidores-de mandatos legales.

Desde el punto de vista metodológico, se pueden considerar entonces múltiples víasalrededor de dos asuntos básicos: las prescripciones dadas desde las leyes y las conductas de quienes ejercen la paternidad. Pero cómo entender la relación de ese objeto que es la legislación con las prácticas de quienes la ejercen: ¿Existe una relación de causalidad entre ellas? ¿tal relación sería unidireccional, bidireccional, de causalidad circular?

Para intentar responder a las preguntas planteadas, y abordadas parcialmente a esta altura del texto, puede considerarse ahora la legislación, la cual es considerada para efectos de este trabajo, como un artefacto, con lo cual podría tomarse como sinónimo de objeto o herramienta, pero Michael Cole, desde la Psicología Cultural, aclara que un artefacto no se reduce a ello. Un artefacto

es un aspecto del mundo material, que se ha modificado durante la historia de su incorporación a la acción humana dirigida a metas. En virtud de los cambios realizados en su proceso de creación y uso, los artefactos son simultáneamente ideales (conceptuales) y materiales. 55 CASTRO-GÓMEZ, Santiago y MENDIETA, Eduardo (coords.). Teorías sin disciplina: Latinoamericanismo, poscolonialidad y globalización en debate. México: Miguel Ángel Porrúa Editores, I998, pp. I2I-I46. p. II4. 


\section{R E V I S T A A N G E L U S N O V U S}

Al ser objeto de la acción humana, podría agregarse entonces el calificativo, cultural. Actualmente se alude a artefacto cultural para hacer referencia a múltiples objetos y dispositivos, atribuyéndose a todo producto de la acción humana, que da cuenta de la cultura de su creador y de sus usuarios; en fin, todo aquello que nos rodea. Pero una descripción de este tipo resulta insuficiente para comprender la naturaleza de tales artefactos. Los artefactos culturales son efectivamente productos de la cultura que aluden a aspectos intangibles (conceptuales o simbólicos) como representaciones, creencias, sensibilidades y, asimismo, tienen un soporte material o físico: leyes, decretos, jurisprudencia, entre otros. De tal manera, su significado excede la base tecnológica y es sensible a las trasformaciones en las mentalidades, la situación política, económica, social y cultural.

Se puede profundizar en este concepto, en el marco de la Psicología Cultural, propuesta por Cole, en cuya concepción, mente y cultura se determinan mutuamente, concibiendo esta última como el medio exclusivo de la existencia humana, que funciona como restricción y como herramienta de la acción, simultáneamente.

Como se mencionó, la naturaleza de los artefactos es dual y, en razón de que ellos integran la cultura, esta deviene simultáneamente material y simbólica, nos siendo reductible a patrones de conducta y productos materiales. La cultura es, según Cole, un mecanismo de control, el pensamiento humano tiene siempre un carácter social y la acción humana siempre está mediada por artefactos. La cultura es entonces constituida y transformada por los artefactos de las generaciones precedentes que se integrarían en un conjunto altamente estructurado.

Desde este punto de vista, la legislación puede concebirse como un artefacto cultural y con ello se incluye, de manera estructural, la cultura y se reconoce que las leyes tienen un aspecto simbólico, además del ya conocido aspecto material. Como artefacto cultural, la legislación es expresión y representación de la cultura: expresión, en tanto es resultado de la actividad intencionada, y representación porque de alguna manera da cuenta de lo que un colectivo considera.

Como artefacto (material y simbólico) de la cultura, la legislación es expresiva, al recoger las ideas dominantes en una época y a la vez es prescriptiva al modelar discursos y prácticas. Así, además de representar la cultura, produce un conjunto de guiones, esquemas y modelos culturales que definen lo canónico y con ello modela comportamientos.

En particular, en el campo de la familia,

[el] Estado mediante innumerables actos jurídicos, leyes, normas selectivas y políticas públicas - por definición obligatorias y de alcance general - contribuye activamente a la sedimentación, e incluso a la prescripción, de ciertos modelos específicos de familias, al volver algunos tipo de arreglos familiares como los apropiados en la medida en que son reconocidos por las leyes, elegibles por los proyectos y 
programas, sujetos de diversos derechos y prerrogativas sociales o de privilegios, exenciones $\mathrm{u}$ obligaciones fiscales, entre otros [...]. El Estado desempeña un papel determinante en la prescripción de ciertos arreglos específicos que son erigidos como modelos de familia y reconocidos como legítimos en la espera pública ${ }^{56}$.

Respondiendo a la pregunta planteada la legislación modela la actividad humana y se trasforma en virtud de ella, ajustándose a la dinámica de la cultura, de allí el valor que tiene como fuente en esta investigación.

Siguiendo a Muñoz, es preciso considerar también, que el Derecho y su base pragmática: la legislación, se construyen sobre la base de una cultura escrita ${ }^{57}$. La comunidad jurídica es una comunidad textual, cuyos integrantes se hayan vinculados alrededor de unos intereses profesionales compartidos, en torno a un limitado segmento de textos, las leyes, alrededor de los cuales desarrollan unas prácticas que también los identifican. Así, comparten ciertos textos y unas formas específicas de interpretarlos, las cuales son fundamentales en la aplicación del derecho a la cotidianidad de las personas que se rigen por él. El legislador sería el miembro más prominente de la comunidad jurídica, productor de textos, sobre los cuales los demás integrantes de la comunidad adelantarán el trabajo que les corresponde. Aquello que leen y escriben los miembros de un grupo socio-profesional específico (el de los juristas) es uno de los componentes que da a la la actividad jurídica y sus productos (las leyes, sentencias, decretos, entre otros), la forma de un artefacto literario.

Como tal, la legislación es "una forma discursiva que resulta de nuestras maneras de producir, acumular e interpretar un corpus textual específico" ${ }^{8}$. Lo escrito es una condición del derecho que le permite ser predecible o calculable, en términos weberianos. Para Muñoz, el Derecho es una "herramienta social" que regula la convivencia, pero siguiendo a Cole, esa mirada sería limitada, porque desconoce el carácter simbólico que el mismo Muñoz reconoce en algún momento en su texto. Sin duda el Derecho no funcionaría sin la escritura y cumple su función social a través de los textos. El Derecho "se construye mediante el trabajo de aquellos que producen unos textos específicos y se (re)construye a través del trabajo de quienes se dedican a interpretarlos” ${ }^{9}$. La escritura fija una buena parte del lenguaje del

RICO, María Nieves; MALDONADO, Carlos. "¿Qué muestra la evolución de los hogares sobre la evolución de las familias en América Latina?" In.: Las Familias latinoamericanas interrogadas - Hacia la articulación del diagnóstico, la legislación y las políticas. Santiago de Chile: CEPAL, UNFPA, I99I, p. 26. MUÑOZ, Daniel. Cultura escrita y derecho - El derecho como artefacto literario. Facultad de Derecho y Ciencias Politicas. Medellín: Universidad de Antioquia, 201 . 


\section{R E V I S TA A N G E U S N O V U S}

Derecho y se ponen en movimiento sólo con la acción de algunos sujetos, apunta el autor. Pero la interpretación no es unívoca; “[...] el texto legal siempre tendrá diversos sentidos y no uno solo que sea incontestable o indiscutible; tal sentido depende del intérprete que se ve obligado a preferir, en el marco de la práctica, uno de los significados posibles según los efectos pretendidos" 60 .

Desde una mirada positivista, se aborda el Derecho en una perspectiva hermenéutica, para da lugar a la necesidad de una actividad de interpretación ligada a la práctica del mismo. Es un mundo de significados, mentalidades y sensibilidades que puede ser leído como un texto, en el marco de una cultura escrita.

\section{Recapitulando, Muñoz reitera que}

Un artefacto literario, es una construcción más compleja que involucra no sólo trozos del mundo físico (como los textos concretos que utilizan las diversas comunidades textuales) sino también aquellas significaciones (carentes de propiedades sensibles) que se fraguan al compás de la práctica que fuere y de los textos que tras ella se esconden. La concepción que proponemos del derecho, por tanto, no lo reduce a un trozo de materia textual.6r

Con ello se aproxima a lo ya planteado en torno a los artefactos culturales. Así, el Derecho es más que un instrumento social. Igualmente otra observación importante que hace Muñoz sobre las fuentes jurídicas es que

[...] detrás del texto de la ley se esconden otros textos, a saber: las exposiciones de motivos documentos en los cuales se deja constancia de las razones de oportunidad y conveniencia para expedir una ley- y los informes solicitados por los congresistas a sus asesores. Legislar, pues, es redactar: así lo atestigua tanto el proceso como el resultado. ${ }^{62}$

Retomando lo abordado, se entiende la legislación como un sistema integrado por distintos artefactos literarios, construidos y reconstruidos en el marco de una cultura letrada, por una comunidad jurídica, cuya acción está mediada por dichos artefactos. Pero los actores sociales que integran esta comunidad tienen distintos lugares y por tanto sus intercambios se constituyen en relaciones de poder.

Para Bourdieu, es preciso asumir la existencia de un campo jurídico, resultado de la pugna entre los distintos elementos que lo constituyen, los cuales no serían el producto de 
consideraciones racionales, ni exclusivamente una respuesta a demandas sociales ${ }^{63}$. Para este autor, el análisis de lo jurídico tiene como telón de fondo al Estado, el cual detenta el monopolio de la razón jurídica y el fortalecimiento de la formación de la burocracia como el aparato a través del cual hace presencia activa socialmente. La razón jurídica es el soporte de la formación burocrática del Estado, el cual respalda la acción del Derecho a partir de la fuerza y en ello radica la eficacia de la razón jurídica.

En esta vía, el Derecho es considerado por Bourdieu como la forma por excelencia del poder simbólico, que sería “[...] ese poder invisible que sólo puede ser ejercido con la complicidad de aquellos que no quieren saber que están sometidos al mismo o que lo ejercen"64. De tal manera, el Derecho es un instrumento de conocimiento y comunicación, que legitima la dominación política de una clase social sobre otra por medio de la violencia simbólica. Esta lucha simbólica entre las clases se dirige a la conceptualización del mundo social de acuerdo a su interés, a través de un poder al mismo tiempo estructurado y estructurante. Interesa al autor cómo se construye y se presenta el Derecho, a partir de las acciones desplegadas por los agentes que intervienen en el campo jurídico. Con este concepto da cuenta de "la existencia de un universo social, relativamente independiente de las demandas externas al interior del cual se produce y se ejerce la autoridad jurídica" ${ }^{65}$. En este espacio de la vida social, determinado por las diversas actividades estructuradas y reguladas al interior del mismo, se desarrolla constantemente una lucha en la cual intervienen múltiples y variados actores, con fuerzas desiguales, que, sin embargo, deben aceptar las reglas propias de ese espacio social que definen sus límites y posibilidades de acción dentro del mismo.

Al tener un marco reglado, altamente estructurado, el Derecho es para Bourdieu ineludiblemente conservador, lo cual no puede perderse de vista al tener la legislación como fuente primaria central. "Las instituciones jurídicas contribuyen universalmente, sin duda, a imponer una representación de la normalidad en relación con la cual todas las prácticas diferentes tienden a aparecer como desviadas, anormales, patológicas" ${ }^{66}$ y allí, paradójicamente, se explica las posibilidades de cambio a partir de las luchas en el campo jurídico, con la participación de distintos grupos sociales, demandando su inclusión y reconocimiento. De tal manera, el campo jurídico tendría unas dinámicas variables, que oscilan entre el equilibrio y el conflicto, las cuales deberían considerarse también.

63 BOURDIEU, Pierre. "La fuerza del Derecho - Elementos para una sociología del Campo Jurídico". In.: BOURDIEU, Pierre. Poder, Derecho y clases sociales. Bilbao: Desclée de Brouwer, 2000, p. 165-223.

64 BOURDIEU, Pierre. "Sobre el poder simbólico". In.: BOURDIEU, Pierre. Poder, Derecho y clases sociales. Op. Cit., p. 88.

65 Ibid., p. 158.

66 Ibid., p. 2 II. 


\section{R E V I S TA A N G E U S N O V U S}

Las disputas teóricas que se presentan en el derecho sobre el papel de sus fuentes, en especial de la jurisprudencia y las leyes, pueden leerse en clave de este sociólogo como una pugna típica al interior de un campo de poder. La creación de las leyes, así como su efecto jurídico son entonces el resultado de la confrontación entre las diferentes fuerzas actuantes al interior del campo jurídico y de la relación que este guarde con otros campos en el escenario social para determinar finalmente que el derecho es un sistema simbólico, producto de la acción de unos agentes sociales. De tal manera, se crea y se recrea en los escenarios sociales y es permeado por la cultura, resultando finalmente como un producto cultural.

Pero el Derecho no se queda sólo en el plano social, llega incluso a la dimensión subjetiva. Bourdieu postuló un efecto de normalización del Derecho, definiendo un adentro y un afuera de tal condición de normalidad que crea $^{67}$; con ello se puede enlazar el planteamiento de Hurstel, cuando al hablar del debilitamiento de la autoridad de los padres plantea que este se produjo en el ámbito social pero se manifiesta en los enunciados del Derecho: "Es allí donde se hace trasmisible, al quedar fijado en palabras, enunciados y significantes que pueden circular de boca en boca" ${ }^{68}$. Así, el Derecho es también aquello que “'instituye' al sujeto: [...] Esta 'institución’ del sujeto es la función propia de la genealogía, el lenguaje jurídico constitutivo de las redes del parentesco"69.

\section{Algunas fuentes jurídicas para el abordaje de la paternidad}

Al tener en cuenta que las leyes son artefactos culturales y literarios que corresponden a contextos específicos, es imposible recomendar fuentes útiles para todos los contextos. Sin embargo, tras la experiencia que representa el estudio de la paternidad en Colombia desde finales del Siglo XIX hasta finales del Siglo XX, por parte de la autora ${ }^{70}$, se pueden proponer, de manera general, categorías de fuentes jurídicas, que posibilitan la comprensión de la manera como la paternidad, como institución, ha sido presentada, las prescripciones que ante ella se han dado y sus transformaciones.

El Derecho Canónico y el discurso religioso. Si se considera la institución de la paternidad en un contexto católico, como el colombiano, bien vale la pena, explorar no solo la legislación civil, sino también el derecho canónico y en él sus códigos vigentes, las

67 BOURDIEU, Pierre. "La fuerza del Derecho - Elementos para una sociología del Campo Jurídico”. Op. Cit.

68 HURSTEL, Françoise. "De los padres “ausentes” a los “nuevos padres”. Op. Cit., p. 296.

69 Ibid., p. 296.

70 Ver PINTO, Leonor Cecilia. La paternidad en Colombia entre i879 y 1979. Op.Cit. y PINTO, Leonor Cecilia. La paternidad en Colombia entre 1980 y Iggr. Op.Cit. 
constituciones apostólicas o dogmáticas y las encíclicas, donde frecuentemente se usa la metáfora familiar para referirse a la Iglesia, y donde frecuentemente se trata al Romano Pontífice como el "verdadero vicario de Cristo y cabeza de toda la Iglesia y padre y maestro de todos los cristianos" ${ }^{\text {1. }}$ Igualmente, a esta figura central se le designa como "el Santo Padre” y se le erige como legítimo representante divino, como padre y como maestro, con autoridad plena sobre la Iglesia en asuntos de fe, costumbres y disciplina y los obispos quedan bajo su autoridad. La obediencia es la única opción, ya que del otro lado estaría la excomunión. Esto representa una oportunidad para conocer sobre el Padre y los ideales que se establecen sobre ella, a través de la figura del Papa ${ }^{72}$. De igual manera, el discurso religioso sobre la familia, los padres, los hombres y las mujeres daría elementos valiosos de análisis. Por ejemplo, el fortalecimiento de la imagen de la madre, a través de la insistencia de la Iglesia Católica en el culto mariano, representa una valiosa fuente que contrapone las imágenes de madre y padre. Para Ramón73, los cultos marianos, además de ser un elemento central en la construcción de identidades nacionales y regionales, han atraído a los historiadores por su dimensión política, asociada al miedo producido por la guerra, la persecución de los católicos (real o imaginaria) o la aparición de símbolos que desafían la autoridad de la Iglesia, esto en la misma vía de los planteamientos de Delumeau ${ }^{74}$. En la exploración de discursos como estos, ante situaciones de inestabilidad política, nacional y mundial, conviene preguntarse por la manera como se presenta la escucha de Dios padre y la intersección de la madre, y los efectos sobre la imagen social del padre.

El Código Civil: En el caso colombiano, la Constitución de i886 era una declaración política que definía las reglas del juego en la distribución del poder público, mientras el Código Civil colombiano7s precisaba la interrelación en los distintos espacios de la vida cotidiana y en particular de la vida familiar. El Código Civil Colombiano estuvo inspirado en el Código Napoleónico, el Derecho Canónico y el Código Civil Español y Chileno y esta parece ser la fórmula inspiradora de los códigos civiles de la época, en diferentes contextos. En

7I DENZINGER, Enrique. El Magisterio de la Iglesia. Barcelona: Editorial Herder, 1963, p. 59I.

72 Para fines del siglo XIX, ver por ejemplo, CONCILIO ECUMÉNICO VATICANO I. Constitución Dogmática Pastor Aeternus. Julio I8 de I87o. Disponible en: http://es.catholic.net/op/articulos/r9352/cat/718/ constitucion-dogmatica-pastor-aeternus.html y LEÓN XIII, Papa de la Iglesia Católica. Enclíclica Arcanum Divinae Sapientiae. 1880, No. 7. Disponible en: http://w2.vatican.va/content/leo-xiii/es/encyclicals/documents/hf_l-xiii_enc_1oo2I88o_arcanum.html

73 RAMÓN, Francisco Javier. La Virgen del Pilar dice... Usos politicos y nacionales de un culto mariano en la España Contemporánea. Zaragoza: Prensas de la Universidad de Zaragoza, 2014.

74 DELUMEAU, Jean. El miedo en Occidente: (Siglos XIV-XVIII). Una ciudad sitiada. Editorial Taurus, Madrid, 1978.

75 REPÚBLICA DE COLOMBIA. Ley 57 de I887 (abril I5). Sobre adopción de códigos y unificación de la legislación nacional. In: Diario Oficial No. 7019, de 20 de abril de 1887. 


\section{R E V I S T A A N GELUS N O V U S}

Colombia, se hubiera esperado el influjo de las ideas de la Ilustración sobre la Ley 57 de I887, pero esas ideas ilustradas fueron disminuidas y reorganizadas por el pensamiento conservador, católico y autoritario que prevalecía a fines del siglo XIX. Al estar contenido en el Código Civil, en Colombia el Derecho de Familia toma una naturaleza jurídica privada, recogiendo del Código Napoleónico la tradición del Derecho Romano, donde la familia era símbolo de estabilidad y seguridad. Resulta importante, entonces, comprender la manera como se concibe la familia y el lugar del padre en el contexto romano para comprender las reglas de la filiación, de parentesco que resultan como referentes a nuestros códigos civiles. Por ejemplo, hay una fórmula romana que el Código Francés y el Colombiano retoman: "Pater is est quem nuptiae demostrant", es decir, padre es quien está demostrado por medio del matrimonio. Es decir, la paternidad se funda sobre un vínculo previo: la conyugalidad y se define por el matrimonio. Padre es quien el matrimonio designa. La paternidad, además, se presume, es incierta, mientras "Mater semper certa est”, la madre es siempre conocida. Así, mientras la maternidad se entiende como un hecho biológico y evidente, en razón del embarazo, la paternidad es dudosa: "pater semper incertus es”.

A partir de allí, un Código Civil como el colombiano, dará cuenta de quién es el padre, cuáles son sus potestades y cómo se construyen las relaciones con su descendencia y su pareja. Conviene seguir las transformaciones de este código en lo que concierne a las relaciones paterno-filiales y maritales.

Leyes sobre la relación Estado-Iglesia y los discursos sobre ello. Se sugiere analizar en términos generales, el proceso de secularización al que asisten nuestras sociedades, a través del análisis de las leyes que abordan la relación Estado-Iglesia. Para Berger ${ }^{76}$ y Marramao77, la secularización es un fenómeno, un acontecimiento histórico, con fuerte influencia sobre la sociedad y la cultura. Ella "Afecta a la totalidad de la vida cultural e ideológica, y puede observarse en el declinar de los temas religiosos en las artes, en la filosofía, en la literatura, y sobre todo en el despertar de la ciencia como una perspectiva respecto al mundo autónoma y eminentemente secular" ${ }^{8}$. Si en el lugar central de la religión está la figura de Dios Padre es preciso analizar qué significa un proceso de secularización en un contexto determinado y cómo podría afectar la imagen social del Padre. Para el caso de Colombia, el fin del Concordato con la Santa Sede, en 1993, se asocia a un cuestionamiento a la figura de Dios Padre y un agravio a su amor, después de que el país fuera consagrado al Sagrado Corazón de Jesús. Se trata de una afrenta al reconocimiento de la omnipotencia de Dios Padre, pero seguramente entre la secularización y la imagen del padre existe una relación causal circular,

76 BERGER, Peter. Para una teoria sociológica de la religión. Barcelona: Kairós, I98I.

77 MARRAMAO, Giacomo. Cielo y tierra. Genealogía de la secularización. Barcelona: Paidós, 1998.

78 BERGER, Peter. Para una teoría sociológica de la religión. Op. Cit., p. I55. 
entendiendo que también la pérdida de la potencia de la figura paterna puede favorecer el proceso de secularización.

La legislación educativa: El padre es indiscutiblemente una figura de autoridad pero resulta importante indagar por competidores que tenga por ese lugar de autoridad, desde otros espacios de socialización, distintos a la familia, como la escuela. La legislación educativa dará cuenta del lugar de los maestros en la socialización de las nuevas generaciones y por tanto, las distancias y acercamientos con la función de los padres en el ámbito familiar. Por ejemplo, para fines del siglo XIX, Colombia se encontraba muy rezagada en materia educativa, si se le compara con otros países. Con la promulgación de la Ley General de Educación en 189279 se otorga al gobierno central la supervisión y regulación de la educación. Esta ley, y su decreto complementario $^{80}$, delegaron a los maestros un lugar de autoridad muy importante. Con ella, tienen plena autoridad en la educación de los niños y deben supervisar su conducta, dentro y fuera de la Escuela, excepto dentro de los límites de la casa paterna. De tal manera, parecía otorgarse al maestro en el espacio público un lugar de autoridad, complementario a la labor del padre en el ámbito doméstico y ese era su límite, resultando conveniente analizar en la legislación educativa las competencias y los límites entre la autoridad de los padres y los maestros, que pueden anticipar rivalidades y fuentes potenciales de conflictos por la autoridad. ¿cuáles son las particularidades de un maestro y cuáles las de un padre? ¿Cuáles son los ideales de uno y de otro que se promueven? ¿cuáles son la relaciones ideales que ese establecen entre ellos? Para el caso colombiano, parece que para la época referida se espera que el maestro encarne la figura de un padre ideal.

Leyes relativas a la ampliación de derechos de las mujeres: En Colombia, a partir de 1932 la potencia paterna, como la concebía el Código Civil de I887, se fue transformando progresivamente. Ley 28 de $1932^{8 \mathrm{r}}$ inauguró una serie de modificaciones que minaron el lugar del padre de potestades absolutas, en lo que respecta al régimen patrimonial del matrimonio, permitiendo a la mujer casada, mayor de 2I años, la libre administración de sus bienes y suprimió la jefatura de la sociedad conyugal en cabeza del marido. Conviene enmarcar estas significativas reformas en las demandas de las mujeres por sus derechos civiles, analizando los discursos sobre ellas, para entender su lugar frente a los hombres. Por ejemplo, para el caso colombiano, se encuentra que el IV Congreso Internacional Femenino (1930) se enmarca en la

79 REPÚBLICA DE COLOMBIA. Ley 89 de 1892 (diciembre 13) Ley de Instrucción Pública. In: Diario Oficial No. 9023 de 24 de diciembre de 1892.

8o REPÚBLICA DE COLOMBIA. Decreto Número 0429 de 1893 (enero 20), por el cual se organiza la Instrucción pública primaria. In: Diario oficial 9,073 de I2 de Febrero de 1893.

8I REPÚBLICA DE COLOMBIA. Ley 28 de 1932 (noviembre I2), sobre reformas civiles (régimen patrimonial en el matrimonio). In: Diario Oficial No. 22.139, del 17 de noviembre de 1932. 


\section{R E V I S T A A N GELUS N O V U S}

conmemoración del primer centenario de la muerte de Simón Bolívar y que ratifica la imagen de un padre fundador de la patria, dador de libertad e inspirador de justicia.

En la misma línea de los avances en el reconocimiento de los derechos de las mujeres está el Decreto 227 de $1933^{82}$, el cual posibilitó su acceso al bachillerato, y esta fue la antesala para el ingreso a la universidad, lo cual tuvo lugar en 1937. Reformas educativas soportadas por el liderazgo de varias mujeres, en el marco de las recomendaciones de la Misión Pedagógica alemana (1924 - 1926), permitieron otro sutil ajuste a la visión tradicional de la familia y con ello al menoscabo de la posición dominante del padre. Por su parte, el Acto Legislativo i de 1936 $6^{83}$, modificó parcialmente la Constitución y ratificó que la ciudadanía era exclusiva para los varones mayores de 2i años, pero posibilitó que las mujeres colombianas, mayores de edad pudieran desempeñarse en cargos que implicaran autoridad o jurisdicción, en las mismas condiciones que se exigieran para los ciudadanos. Este tipo de reformas, entre muchas otras, implicarían la pérdida de potestades que en el pasado serían exclusivamente paternas.

Resulta importante destacar que este proceso de lucha por los derechos no está exento de conflictos y que la legislación de la época puede dar cuenta de intentos de sostener al padre en un lugar hegemónico, retomando viejas fórmulas. Así por ejemplo, en Colombia, la Ley 45 de $1936^{84}$, al definir la patria potestad, condiciona su ejercicio por parte de la mujer a la ausencia del padre, a la guarda de las buenas costumbres y al hecho de no incurrir en segundas nupcias, requisitos no exigidos a él. Igualmente, en 1939, con el Decreto $1003^{85}$, se estableció que la mujer casada o viuda llevara, en los diferentes actos de la vida civil, el apellido de su marido precedido de la partícula de. Sin embargo, con el Acto Legislativo No. I de $1945^{86}$ que reformó la Constitución, se reconoció la ciudadanía a la mujer, "condición clave para elegir y ser elegido y para desempeñar empleos públicos que lleven anexa autoridad o jurisdicción. Sin embargo, la función del sufragio y la capacidad, para ser elegido se reserva a los varones”. ${ }^{87}$ Finalmente, en 1954, tras la presión de un sector femenino de la sociedad colombiana, las mujeres conseguirían el reconocimiento al derecho político de elegir y ser elegidas.

82 REPÚBLICA DE COLOMBIA. Decreto 227 de 1933 (febrero 2), por el cual se dictan disposiciones sobre enseñanza secundaria para señoritas. In: Diario Oficial No. 22215 de 1933

83 REPÚBLICA DE COLOMBIA. Acto Legislativo i de 1936 (agosto 5), reformatorio de la Constitución. In: Diario Oficial No. 23.263 de 22 de Agosto de 1936.

84 REPÚBLICA DE COLOMBIA. Ley 45 de 1936 (marzo 5), sobre reformas civiles (filiación natural). In: Diario Oficial No. 23.147 de 30 de marzo de 1936

85 REPÚBLICA DE COLOMBIA. Decreto Ioo3 de 1939 (mayo io), sobre el registro civil y el registro de reconocimiento de hijos naturales. In: Diario Oficial No. 24.076, del 23 de mayo de 1939.

86 REPÚBLICA DE COLOMBIA. Acto Legislativo No. I de 1945 (febrero 6), reformatorio de la Constitución Nacional. In: Diario oficial No 25.769, de 17 de febrero de 1945. REPÚBLICA DE COLOMBIA. Acto Legislativo No. I de 1945 (febrero 6). Op. Cit., Artículo 3. 
Independiente del orden jerárquico que pueda establecerse entre las demandas sociales de las mujeres y el paulatino despliegue del liberalismo económico en Colombia, como causas de la ampliación del espectro de derechos de las mujeres, es claro que todos estos factores contribuyeron a minar el lugar hegemónico que hasta los años 20 tenía el padre, quien fuera el depositario exclusivo de la autoridad y el poder sobre la esposa y los hijos.

Leyes relativas a la configuración de un complejo tutelar. Bajo la concepción de un padre, a manera de un padre, con poder y autoridad ilimitados, los infantes, como todo y como todos, estarían a su cargo y no se cuestionaría su bienestar. Sin embargo, la pobreza, los problemas sociales derivados de las guerras internas o externas, podrían impactar la población, derivando en la vagancia y la criminalidad. Los niños expósitos, vagos y malentretenidos, cuestionaría la tutela y la autoridad paterna, siendo precisa la definición de una política social, en respuesta a las problemáticas. El "Ensayo sobre la desigualdad de las razas humanas”, del francés Joseph Arthur Gobineau, publicado entre 1853 y I855, alentaría la asociación entre raza, racismo, eugenesia y progreso, en donde condiciones raciales son percibidas como factores de atraso y de decadencia. Los niños no escaparían al influjo de la degeneración de la raza y al estar asociados al porvenir serían objeto de la mirada de los científicos sociales de la época. De acuerdo con Donzelot, se configuraría así un Complejo Tutelar, que es la articulación entre distintos saberes recogidos en profesiones que se insertan en los aparatos judicial, asistencial y educativo existentes, cuyo objetivo de intervención será, por un lado, la infancia que no recibió los cuidados y la educación ideal y, por otro, la infancia peligrosa, que delinque ${ }^{88}$. La familia quedaría atrapada en esa red y el padre sería reemplazado por el Juez y la familia por un conjunto de especialistas en ella. El saber médico contribuiría a la reconfiguración de ese complejo tutelar sobre los niños, que ya venía desde la Colonia, pero que desde principios del Siglo XX en Colombia, articularía nuevos saberes expertos, representados por distintos profesionales y también nuevas instituciones, que procurarían responder al ideal de lo moderno.

Resultan de gran relevancia las leyes asociadas a la configuración y fortalecimiento de este complejo tutelar, porque él sustituye al padre ante el incumplimiento de sus funciones, bien sea por negligencia o por incapacidad. En Colombia, por ejemplo, con los juzgados de Menores $^{89}$, los niños expósitos y delincuentes, dejaría de ser competencia de la justicia penal ordinaria y la actuación del Juez "[Deben] actuar en los juicios más como padres que como juzgadores implacables: por eso la misma ley prescribió [...] que el Juez de Menores debía ser

88 DONZELOT, Jacques. La policía de las familias. Valencia: Editorial Pre-textos, 1979.

89 Ver por ejemplo: REPÚBLICA DE COLOMBIA. Ley 98 de 1920 (noviembre 26), por la cual se crean Juzgados, casas de reforma y corrección para menores. Diario oficial. Año LVI. No. 17440 y I744I. I de diciembre de 1920 . 


\section{R E V I S TA A N G E U S N O V U S}

casado, padre de familia y asesorado por un médico siquiatra para el estudio y terapéutica de la salud física y mental de los menores”.90

El Complejo Tutelar se iría intrincando y especializando con la aparición de nuevas instituciones y nueva legislaciones y es preciso hacer seguimiento a sus cambios y continuidades, así como los discursos que lo justifican y su referencia al papel del padre, que seguramente oscilará entre un padre carente o un padre irresponsable. El cruzamiento con los indicadores sobre población y nivel de vida y las historias de los padres, recogidas en los archivos, podrían dar cuenta si se trata de lo uno o lo otro.

A partir de 1989 , en el marco de convenios internacionales ${ }^{91}$, las leyes indicaron que los niños dejan de ser objetos de protección a ser sujetos de derechos. Con ello, la infancia deja de ser conceptualizada alrededor de la dependencia o subordinación de los padres y adultos, pasando a ser una etapa de desarrollo gradual de la autonomía personal, social y jurídica y ello supondría una suerte de emancipación progresiva de la potestad paterna que en otrora fuera absoluta. Cabe la pregunta: ¿De qué manera este nuevo concepto de niño y adolescente transforma el lugar del padre? Si bien las relaciones jerárquicas que la autoridad parental plantea no están en cuestión directamente, el niño es ahora un sujeto y no un objeto del cuidado parental, el Estado y la Sociedad, por lo menos desde el discurso jurídico.

Leyes alusivas al esclarecimiento de la paternidad y la asistencia en la procreación. En los años 70 y 80 nuevos descubrimientos permitieron técnicas cada más sofisticadas de esclarecimiento de la paternidad. Con la sofisticación de las pruebas se confirmaría que el reconocimiento de los hijos ya no sería un asunto voluntario, a discreción del progenitor o un asunto que exija la fuerza del testimonio de un tercero para presumirlo. Jueces, Defensores de Familia, se situarían como autoridad por encima del padre y él no podría oponerse a la investigación de su progenitura. Con las pruebas centradas en la evidencia biológica, el testimonio para reconstruir la historia de la pareja y la inferencia de las relaciones sexuales a partir de ello, perdería el valor como única prueba. La máxima que alguna vez rezó "Pater is est quem nuptiaet demostrant” es para siempre cosa del pasado, así como la autoridad paterna que la sustentaba. En lo sucesivo la paternidad no será presumida, ni demostrada por el matrimonio, ella podrá ser esclarecida por una prueba científica, la cual tendrá cada vez noviembre de 1989 en la Asamblea General de las Naciones Unidas. y para el caso colombiano: REPÚBLICA DE COLOMBIA. Ley I2 de I99I (enero I2). Convención Internacional sobre los derechos del Niño. Por medio de la cual se aprueba la Convención sobre los Derechos Del Niño adoptada por la Asamblea General de las Naciones Unidas el 20 de noviembre de 1989. Diario oficial. No. 39.640 de enero 22 de i991. 
mayores niveles de confiabilidad. Pero ¿qué significó para el lugar social del padre y para la relación padre-hijo un reconocimiento basado en la evidencia biológica, aún contraria a la voluntad de un padre? ¿Qué consecuencias tuvo a nivel social y subjetivo la apelación a una prueba "científica" para establecer la paternidad? ¿Acaso la paternidad queda reducida a un hecho biológico, a una relación consanguínea? ¿Sobre qué se funda padre-hijo cuando el padre se niega al reconocimiento social del hijo pese a la prueba en contra? Estas son preguntas que caben para distintos contextos.

Las técnicas de reproducción humana asistida y particularmente la inseminación artificial: intrauterina, in vitro, con donante o post-mortem, abrían la posibilidad de que el padre pudiera ser asistido e incluso reemplazado ante la dificultad para engendrar. Si bien la maternidad subrogada o gestación por sustitución daba también a las mujeres la posibilidades ser sustituidas en la labor de la gestación, en el marco de una sociedad patriarcal, tal sustitución no será asumido de igual manera en hombre que en mujeres. Así, con los adelantos científicos y tecnológicos, la función de procreación, de base biológica, también podría ser intervenida por la acción humana.

De tal manera, la pregunta que queda es ¿quién es el padre y qué lo sustenta ahora?

Leyes relativas al reconocimiento de diversas formas familiares. La manera como se organiza la familia también se modificó ampliamente. Retomando a Gutiérrez de Pineda ${ }^{92}$ es preciso recordar que la familia no es una entidad única, inmutable, ella existe bajo múltiples formas, de carácter inestable, que en un proceso evolutivo se ajustan a las nuevas exigencias de sus entornos sociales y culturales y simultáneamente los transforman. Analizar las leyes que reconocen, definen y regulan las diversas tipologías familiares a las que asistimos, también permite acercarnos a la búsqueda de respuestas a la pregunta por quién es el padre y cuáles son sus particularidades.

\section{A modo de síntesis}

La paternidad es una institución sobre la cual han influido fuerzas políticas, económicas, sociales en tanto el padre es potencia que tiene esas tres naturalezas: política, económica y social.

Investigar la paternidad como institución, en una perspectiva historiográfica, colocaría en un lugar central el análisis de los cambios y continuidades en la legislación que se 


\section{R E V I S T A A N GELUS N O V U S}

promulga y que atañe a la familia, a la luz de los contextos en que la legislación se produce y se recibe. Tal pesquisa no podría desconocer las prácticas de los padres, definidas por elecciones subjetivas y atravesadas por condiciones de clase, raza y etnicidad. Estas prácticas podrían acercarse o distanciarse de las prescripciones que las leyes establecen y tales distanciamientos, al ser juzgados como comportamientos desordenados o anómalos, podrían motivar nuevas leyes procurando el control de las conductas y con ello, el restablecimiento del orden.

Se trata entonces de una perspectiva sistémica que reconoce en las prescripciones, las prácticas y los contextos, un sistema donde la causalidad circular es característica. Así, las prescripciones, las prácticas y las condiciones políticas, económicas, sociales, culturales, terminan definiendo qué es la paternidad, como institución, en un determinado tiempo y lugar.

Como institución, la paternidad está fundamentada e instituida sobre las leyes y la manera como el historiador las comprenda definirá las posibilidades que tenga ante esta importante fuente primaria. Una mirada amplia, enriquecida por un enfoque transdisciplinar del asunto, amplificaría también las posibilidades para la labor historiográfica. Desde los aportes de la Psicología Cultural, la Sociología y el Derecho se reconoce que su compendio, la legislación, es un artefacto cultural y literario, producto de las interacciones en un campo de poder. Como artefacto cultural, el trabajo con la legislación posibilitaría indagar por la representación que hace de la cultura en la cual se inscribe y la prescripción de modelos culturales, guiones y roles. Como artefacto literario, interesarían las comunidades letrada en donde se producen, acumulan e interpretan. Y el hecho de reconocer el Derecho como la forma por excelencia del poder simbólico, instrumento de conocimiento y comunicación, que legitima la dominación política de una clase social sobre otra, por medio de la violencia simbólica, posibilitaría indagar por las fuerzas en pugna que, al interior de este campo de poder, tienen lugar por alcanzar el monopolio de la razón jurídica.

Aunque las leyes son obviamente particulares a cada contexto, para abordar la paternidad como institución, en una perspectiva historiográfica, se pueden considerar como fuentes la legislación relativa a un amplio espectro de temáticas, tales como: la relación EstadoIglesia, la educación, la ampliación de los derechos de las mujeres, la consolidación del complejo tutelar sobre los niños, el esclarecimiento de la paternidad y la asistencia en la procreación y las diversas tipologías familiares. Además., el derecho canónico, las constituciones dogmáticas y las encíclicas pueden representar importantes fuentes de información al respecto.

Recebido: 13/o9/2019

Aceito: 02/10/2019 